\title{
A CRÍTICA DA GESTÃO DA DIVERSIDADE NAS ORGANIZAÇÕES
}

\section{RESUMO}

Este artigo trata da gestão da diversidade nas organizações, analisando-a criticamente como parte integrante da ideologia tecnocrática, que procura deslocar o tratamento das desigualdades sociais do âmbito político para a administração de recursos humanos das empresas. A partir da análise da literatura estrangeira e nacional sobre o tema, infere-se que a gestão da diversidade surgiu como resposta dos administradores norte-americanos às políticas de ação afirmativa das décadas de 1960 e 1970. Essa literatura defende que a gestão da diversidade é mais efetiva para o enfrentamento das desigualdades sociais por usar critérios de meritocracia e possibilitar atingir benefícios econômicos para os indivíduos e as empresas. A transposição dessas práticas para o contexto brasileiro, porém, encontra um elemento complicador em sua adoção quando se considera a ideologia da democracia racial brasileira, que mascara o preconceito e entra em tensão com a ideologia da gestão da diversidade.

\section{Mario Aquino Alves \\ Mackenzie e FGV-EAESP \\ Luis Guilherme Galeão-Silva FGV-EAESP}

\begin{abstract}
This paper critically analyses diversity management in organizations as an inherent part of technocratic ideology, which aims to displace the treatment of social inequality from the political instance to the human resources management of companies. From the analysis of the international and national literature on the subject it is discovered that diversity management has emerged as a response of North American managers to the affirmative action policies of the 1960's and 1970's. This literature advocates that diversity management is more effective to deal with social inequalities because it is based on meritocracy and makes achievable to reach economic benefits both to individuals and companies. The transplantation of these practices into the Brazilian context, on the other hand, bumps into a complication in terms of their adoption face to the myth of the Brazilian racial democracy, which masks prejudice and gets in tension with the ideology of diversity management.
\end{abstract}

PALAVRAS-CHAVE Diversidade, ação afirmativa, gestão da diversidade, teoria crítica, racismo.

KEY WORDS Diversity, affirmative action, critical theory, racism. 


\section{INTRODUÇÃo}

Independentemente das perspectivas adotadas - por exemplo, de gênero, etnia, idade, religião ou orientação sexual - evidências dão conta de que o perfil da força de trabalho vem se diversificando cada vez mais nas últimas décadas nos Estados Unidos e na União Européia (Wentling e Palma-Rivas, 1998), levando pesquisadores de diversas áreas a intensificarem seus esforços na investigação desse fenômeno, tal como apontam Nkomo e Cox Jr. (1999).

Em geral, a gestão da diversidade tem sido defendida com base em dois pontos. Primeiro, programas internos de empresas voltados à diversidade seriam socialmente mais justos do que políticas de ação afirmativa - impostas por uma legislação que remonta às lutas por direitos civis nos Estados Unidos durante as décadas de 1960 e 1970 -, uma vez que se baseiam na meritocracia e não no favorecimento. Segundo, um bom gerenciamento da diversidade de pessoas nas organizações conduziria à criação de vantagem competitiva, o que, em tese, elevaria o desempenho da organização no mercado, tendo em vista a influência positiva de um ambiente interno multicultural, com membros de distintas experiências e habilidades.

Em uma sociedade com graves problemas de justiça, como a brasileira, há quem defenda que a valorização da gestão da diversidade teria um aspecto altamente positivo por representar iniciativas promissoras de inclusão social (Fleury, 2000). No Brasil, vários grupos são historicamente marginalizados e seus membros excluídos do exercício da cidadania. As poucas políticas públicas de ação afirmativa têm eficácia duvidosa, como mostra a história recente. Nesse contexto, seriam bemvindas, portanto, práticas empresariais inovadoras, como a gestão da diversidade por empresas - brasileiras ou não - que atuam no contexto brasileiro.

No entanto, pode-se perguntar: seria a gestão da diversidade capaz de criar uma solução para a exclusão de grupos tradicionalmente discriminados? Ou, ainda, a gestão da diversidade não poderia ser uma forma, ideologicamente articulada, de esconder conflitos que surgem, prioritariamente, do campo social, como por exemplo, da existência de preconceitos contra grupos sociais marginalizados? Conseguiria a gestão da diversidade reaver os direitos desses grupos por meio de uma ação afirmativa?

$\mathrm{O}$ presente texto originou-se de um trabalho que buscou responder às perguntas anteriormente formuladas. Seu principal objetivo é contribuir com uma discussão crítica ao debate sobre as implicações sociais e políticas da implementação de modelos estrangeiros, especialmente norte-americanos, de gestão da diversidade por empresas instaladas no Brasil

A primeira parte trata dos procedimentos metodológicos que nortearam a pesquisa da qual este artigo se originou. Logo em seguida é feita uma contextualização do tema "diversidade" nos Estados Unidos, onde se originaram tanto as idéias de ação afirmativa quanto de gestão da diversidade, a partir dos principais tópicos apontados na literatura acadêmica, com especial destaque para a separação que se faz entre ação afirmativa e gestão da diversidade. Depois, analisa-se a adoção da gestão da diversidade e da ação afirmativa na realidade brasileira por meio de sua relação com o racismo ou o preconceito racial. Por fim, baseando-se em um aporte da Teoria Crítica, oriunda da chamada Escola de Frankfurt, discute-se a dificuldade de tratamento da questão do preconceito e do racismo no Brasil, mascarados por uma ideologia que os nega, para, na última seção deste artigo, tratar da análise crítica da gestão da diversidade, tanto de uma maneira geral, como especificamente no contexto brasileiro.

\section{A PESQUISA E 0 MÉTODO}

Este artigo é decorrente de uma pesquisa qualitativa crítica, desenvolvida a partir de um estudo de caráter exploratório. O objetivo principal da referida pesquisa era incrementar o conhecimento sobre o fenômeno das práticas de gestão da diversidade nas organizações, problematizando-as a partir de uma revisão da literatura internacional e nacional sobre o tema.

Em relação à literatura estrangeira, foi adotado o seguinte procedimento de identificação de artigos para análise: primeiro, foram selecionados os artigos que seriam o material de análise da pesquisa. Para isso, foi realizada uma busca na base de dados Proquest, ou ABI/Inform Global ${ }^{\circledR}$. A estratégia de pesquisa baseouse no emprego da palavra "diversity" no campo de busca, restringindo a pesquisa aos artigos dos periódicos acadêmicos referendados - peer-reviewed. Tal expediente trouxe como resultado 215 artigos, nos quais a palavra "diversity" foi empregada.

No que diz respeito à literatura nacional, fez-se um levantamento bibliográfico correspondente ao período entre 1997 e 2002 nas seguintes fontes: Anais do Enanpad, Revista de Administração da USP - Rausp - 
Revista de Administração de Empresas da FGV - RAE Revista de Administração Contemporânea da Anpad RAC - e Organização E Sociedade da UFBA. Apenas dois trabalhos explicitamente falavam sobre a questão da diversidade, ambos de Fleury (1999; 2000).

Tanto os artigos acadêmicos internacionais quanto os nacionais selecionados foram submetidos a uma análise de conteúdo, segundo técnicas e procedimentos apresentados por Bardin (1977), com o intuito de se levantar categorias temáticas sobre a questão da diversidade nesses periódicos em Administração.

\section{O CONCEITO DE DIVERSIDADE NA LITERATURA DE ADMINISTRAÇÃO}

A partir da análise de conteúdo realizada com os periódicos acadêmicos em Administração, pode-se observar que "diversidade" refere-se a uma variedade de atributos de indivíduos e grupos. Segundo essa perspectiva, as organizações deveriam perceber as qualidades de seus consumidores e funcionários. A passagem a seguir revela o sentido com que o termo é, em geral, usado nos periódicos acadêmicos da área.

A diversidade inclui todos, não é algo que seja definido por raça ou gênero. Estende-se à idade, história pessoal e corporativa, formação educacional, função e personalidade. Inclui estilo de vida, preferência sexual, origem geográfica, tempo de serviço na organização, status de privilégio ou de não privilégio e administração ou não administração (Thomas, apud Nkomo e Cox Jr., 1999, p. 334-335).

A análise revelou duas categorias relevantes para o estudo da diversidade: "gestão da diversidade" e "ação afirmativa". A primeira dessas categorias, "gestão da diversidade", diz respeito a uma prática gerencial que pretende substituir ações afirmativas e práticas de equal employment opportunity - acesso igualitário ao trabalho (Gilbert, Stead e Ivancevich, 1999; Kelly e Dobbin, 1998). Dessa maneira, decidiu-se, em primeiro lugar, desenvolver o conceito de ação afirmativa para, em seguida, tratar do conceito de gestão da diversidade.

\section{Ação afirmativa}

A idéia de ação afirmativa baseia-se na compreensão de que os fenômenos sociais não são naturais, mas resultado das diversas interações sociais; assim, haveria necessidade de intervenção política na reversão do quadro de desigualdade que se observa em uma dada sociedade. Nesse sentido, entende-se ação afirmativa como um conjunto de políticas específicas para membros de grupos sociais atingidos por formas de exclusão social que lhes negam um tratamento igualitário no acesso às diversas oportunidades. Seu objetivo é superar os efeitos de um passado de discriminação, garantindo que pessoas ou grupos discriminados possam competir, igualitariamente, com membros dos grupos favorecidos ou, de maneira mais controversa, atingir igualdade completa (Hodges-Aeberhard, 1999).

No caso dos Estados Unidos, por exemplo, medidas em prol do acesso igualitário ao trabalho ganharam espaço na agenda pública nos anos 1960, em resposta à luta pelos direitos civis. Os governos Kennedy e Johnson, de 1961 a 1968, introduziram leis - dentre as quais, o Civil Rights Act, de 1964 - que proibiam as diversas agências governamentais de discriminarem seus candidatos a emprego com base em cor, religião e nacionalidade, estimulando-as para que usassem de ação afirmativa na contratação de seus empregados. As novas leis também incentivavam as empresas contratadas pelo governo federal a se valerem de ação afirmativa para garantir igualdade de oportunidade para membros de minorias e deficientes físicos, proibindo qualquer forma de discriminação (Oliveira, 2001; Hodges-Aeberhard, 1999).

Em outros países, medidas contra a discriminação étnica e de gênero têm sido igualmente implementadas. Na União Européia, por exemplo, tais leis tratam de questões relativas ao multiculturalismo resultante dos fluxos migratórios recentes. Já na África do Sul, objetivam desmontar formas discriminatórias herdadas do regime de apartheid (Hodges-Aeberhard, 1999; Human, 1993; Scott, Amos e Scott, 1998).

\section{Da ação afirmativa à gestão da diversidade}

De forma genérica, entende-se por gestão da diversidade a adoção de medidas administrativas que garantam que os atributos pessoais, ou de grupo, sejam considerados recursos para melhorar o desempenho da organização (Thomas, 1990). Os artigos pioneiros sobre o tema nos Estados Unidos apontam que a adoção dessa prática administrativa resulta, primeiro, no restabelecimento de um princípio meritocrático e, depois, em benefícios econômicos para indivíduos e organizações, desvinculados de qualquer sentido político explícito.

O primeiro trabalho de relevância a usar o termo "gestão da diversidade", de acordo com a literatura consultada, foi o de R. Roosevelt Thomas (1990), em artigo para a Harvard Business Review, em que defen- 
dia a necessidade da substituição das políticas públicas de ação afirmativa por mecanismos de gestão da diversidade. Para o autor, seria necessário mudar a perspectiva da inclusão de minorias, negros e mulheres nas empresas norte-americanas, uma vez que a ação afirmativa estaria contrariando o princípio da meritocracia e, dessa forma, não geraria exemplos para os jovens dos grupos discriminados se espelharem em sua carreira profissional - as admissões ou promoções de membros desses grupos seriam percebidas como não merecidas por outros funcionários e também por jovens desses grupos.

Taylor Cox Jr. e Stacy Blake (1991) foram os primeiros a defender as vantagens da gestão da diversidade sob a perspectiva do desempenho econômico: redução dos custos com turnover e absenteísmo - especialmente entre as minorias incluídas; atração de funcionários talentosos para a empresa; sensibilização para as novas culturas que formam o mercado; aumento da criatividade e da inovação na empresa; aumento da capacidade de resolução de problemas; aumento da flexibilidade do sistema administrativo (Cox Jr. e Blake, 1991).

Esse viés gerencialista para o conceito de diversidade desenvolveu-se como uma decorrência das mudanças na economia e na política estadunidenses. Por um lado, a ação afirmativa perdeu força com o neoconservadorismo da Era Reagan e, por outro, os novos grupos sociais - imigrantes latinos e asiáticos - passaram a demandar um tratamento igual ao dispensado aos negros (Kelly e Dobbin, 1998).

\section{0 foco prescritivo da literatura de gestão da diversidade}

Para uma boa parte da literatura estrangeira, a gestão da diversidade implica, primeiro, definir certas características como parâmetro para diagnosticar a diversificação ou a homogeneidade da organização (Gilbert, Stead e Ivancevich, 1999). Na literatura analisada, são encontrados três tipos de definições dos grupos discriminados.

Em um primeiro tipo, esses grupos são definidos como identidades. Por identidade entende-se um conjunto de atributos que permitem o reconhecimento de uma pessoa como membro de um certo grupo ou como um ser singular (Nkomo e Cox Jr., 1999). No entanto, esse conceito é complexo e de difícil operacionalização - para que se estabeleça uma medida de identidade, faz-se necessário definir operacionalmente quais características serão observadas e como serão agrupadas. Ocorre que identidade não é uma variável discreta, isto é, marcada por oposições binárias; a identidade de cada pessoa é, em realidade, composta por várias identidades (Nkomo e Cox Jr., 1999).

O segundo tipo é a minoria (Gilbert, Stead,
Ivancevich, 1999). Minoria é um termo sociológico que desconsidera o número de membros do grupo, mas contempla sua disposição de poder na sociedade. No caso, uma minoria dispõe de pouco poder e, por isso, depende da arbitrariedade de outro grupo - a maioria. Essa é a terminologia mais usada para se referir aos grupos favorecidos por ações afirmativas.

O terceiro tipo de definição é o histórico. O que caracteriza essas definições é uma leitura crítica das relações intergrupais. A formação dos grupos é um produto das contradições da sociedade. Assim, os grupos são formas de valorização ou desvalorização social (Ellis, 1994; Newman, 1997).

A gestão da diversidade tornou-se uma prática bastante difundida no contexto norte-americano. Porém, como apontam as obras mais gerencialistas consultadas, sua implementação não é fácil. Dentre os principais obstáculos apontados estão o ceticismo dos próprios funcionários das empresas em relação aos programas e sua efetividade; uma atitude preconceituosa em relação a colegas ou chefes que são beneficiários desses programas; e as dificuldades em modificar rotinas de administração de recursos humanos para incluir a questão da diversidade (Austin, 1997; Milliken e Martin, 1996; Barry e Bateman, 1996; Wise e Tschirhart, 2000).

Em geral, a implementação de práticas de gestão da diversidade implica mudanças que vão além de meros procedimentos administrativos, abrangendo mudanças culturais (Gilbert, Stead e Ivancevich, 1999) e cognitivas (Schneider e Northcraft, 1999). Para que sejam superadas as dificuldades, uma parte da literatura aponta mecanismos prescritivos que facilitariam a gestão da diversidade. Alguns, por exemplo, preconizam uma reestruturação das políticas de recursos humanos, focalizando o desenho de planos de carreira, a valorização da família; a criação de formas de tutoria - mentoring - grupos de discussão - diversity councils - e compensações para adoção da diversidade; e o estabelecimento de garantias sobre a lisura dos processos de valorização da diversidade (Gilbert, Stead e Ivancevich, 1999). Para uma comparação entre a ação afirmativa e a gestão da diversidade, ver Quadro 1.

\section{AÇ̃̃o AFIRMATIVA E GESTÃo DA DIVERSIDADE NO BRASIL}

Apenas nos anos 1990 os governantes brasileiros reconheceram a discriminação de negros no mercado de trabalho como um problema social, a partir da luta 
dos movimentos sociais por políticas de ação afirmativa (Soares, 2000). As formas mais efetivas de pressão emergiram em fóruns internacionais a partir das denúncias, formuladas por sindicalistas, de descumprimento, por parte do governo brasileiro, dos compromissos que assumiu ao ratificar, em 1965, a Convenção $n^{\circ} 111$ da Organização Internacional do Trabalho - OIT - que dispõe sobre a Discriminação no Emprego e na Ocupação (Bento, 2000).

Desde 1995 o governo brasileiro vem manifestado interesse no combate à discriminação no mercado de trabalho. Para tanto, solicitou a cooperação técnica da OIT no sentido de efetivar e implementar políticas que promovessem a igualdade de oportunidades e de tratamento no emprego e na ocupação. Em decorrência, foi constituído, pelo Ministério do Trabalho, o Grupo de Trabalho para Eliminação da Discriminação no Emprego e Ocupação - Gtedeo - de composição tripartite - governo, trabalhadores e empresários - que assumiu a missão de elaborar um Plano de Ações para eliminação da discriminação no mercado de trabalho (Ministério do Trabalho, 2001).

No Programa de Cooperação Técnica OIT/Ministério do Trabalho, a questão da discriminação foi centrada em categorias, construindo ações que se voltavam primeiramente para gênero e raça, nas quais são encontrados os grupos mais discriminados. O objetivo posterior era contemplar todos os grupos, levando em consideração que a abordagem, as estratégias e as metodologias poderiam ser diferentes e específicas para cada um (Ministério do Trabalho, 2001).

Sincronicamente, há um crescente movimento nas empresas, principalmente em multinacionais norteamericanas, no sentido de adotar programas de gestão da diversidade. Esse movimento, contudo, não vem acompanhado de um aprofundamento da literatura na- cional sobre o tema. Os movimentos sociais antidiscriminação e de responsabilidade social das empresas é que têm sido os principais agentes de difusão de práticas de gestão da diversidade para empresas brasileiras.

A literatura acadêmica brasileira ainda é incipiente (Bento, 2000); o pioneiro trabalho acadêmico sobre a gestão da diversidade no Brasil foi apresentado por Maria Tereza Leme Fleury, no Enanpad, em 1999, e publicado na RAE em 2000 (Fleury, 2000). Nesse trabalho são apresentadas algumas iniciativas de implantação de programas de administração - ou gestão - da diversidade em empresas instaladas no Brasil, sobretudo multinacionais norte-americanas (Fleury, 2000).

\section{ELEMENTOS PARA A CRÍTICA DA GESTÃO DA DIVERSIDADE}

A intenção desta parte do trabalho é questionar os programas de gestão da diversidade e sua implementação no Brasil, atividade que implica criticar e desvelar a ideologia que está em sua base. Seguindo uma linha clássica de definição, "ideologia" expressa uma falsa consciência sobre práticas sociais contraditórias, que correspondem à ligação entre a existência material das pessoas e sua consciência (Marx e Engels, 1998). Segundo os teóricos da Escola de Frankfurt, são ideológicas as manifestações do pensamento forjadas na dinâmica de relações sociais naturalizadas (Horkheimer e Adorno, 1985), expressando uma visão limitada e distorcida da realidade (Held, 1980).

A gestão da diversidade, quando importada para o contexto brasileiro, é convertida tendo por base duas ideologias tipicamente nacionais, a saber: a ideologia tecnocrática e a ideologia da democracia brasileira. Essas duas formas de ideologia trazem matizes específi-

Quadro 1 - Comparação entre ação afirmativa e gestão da diversidade.

\begin{tabular}{|c|c|c|}
\hline VARIÁVEIS & AÇÃO AFIRMATIVA & GESTÃO DA DIVERSIDADE \\
\hline Grupos atingidos & $\begin{array}{l}\text { Minorias, grupos discriminados: negros, } \\
\text { mulheres e deficientes físicos }\end{array}$ & $\begin{array}{l}\text { Todas as diferentes identidades presentes nas em- } \\
\text { presas: etnias, religiões, gênero, orientação sexual etc }\end{array}$ \\
\hline Efeitos nas empresas & $\begin{array}{l}\text { Pressões coercitivas externas provocam } \\
\text { mudanças nos processos de recrutamen- } \\
\text { to, seleção e treinamento; imposição de } \\
\text { cotas }\end{array}$ & $\begin{array}{l}\text { Diversidade passa a ser uma vantagem competitiva: } \\
\text { atração de funcionários talentosos; sensibilização para } \\
\text { novas culturas / novos mercados; potencial aumento } \\
\text { da criatividade e da inovação nas empresas; aumen- } \\
\text { to da capacidade de resolução de problemas; au- } \\
\text { mento da flexibilidade do sistema administrativo }\end{array}$ \\
\hline
\end{tabular}


cas para a gestão da diversidade em nosso meio, distintas dos pressupostos originalmente elaborados em seus contextos de origem. Será visto cada uma dessas ideologias em separado para, em seguida, analisar limites e condicionantes da gestão da diversidade no Brasil.

\section{A ideologia tecnocrática}

$\mathrm{Na}$ consolidação do capitalismo, a racionalidade técnica fez surgir formas de ideologias voltadas para a afirmação dos administradores como classe social dominante. Dentre elas, a ideologia tecnocrática é aquela que se expressa por meio da tentativa de retratar a administração de empresas como uma função neutra, baseada em uma cientificidade moderna que possui gestores especialistas e técnicos com influência e responsabilidades limitadas (Alvesson, 1987).

A racionalidade técnica constitui-se no aspecto da razão que norteia a organização da sociedade capitalista centrada no mercado. Por meio das mais avançadas e produtivas tecnologias disponíveis, um crescente fluxo de benefícios econômicos é gerado. Assim sendo, a tecnologia avançada é entendida como uma coisa boa em si mesma (Horkheimer e Adorno, 1985), criando um imperativo técnico que subordina todas as outras esferas da atividade humana. As questões políticas são redefinidas, reduzidas a problemas técnicos formalizados e funcionalizados. De acordo com Marcuse (1973, p. 152):

A racionalidade científica favorece uma organização social específica precisamente porque projeta mera forma [...] que pode atender praticamente a todos os fins. A formalização e a funcionalização constituem a 'forma pura' de uma prática social concreta.

A força de trabalho vem sendo disciplinada de acordo com o ideal de produtividade, e suas necessidades devem ser subordinadas à esfera do consumo. Aqui ocorre, portanto, um segundo mecanismo ideológico importante: a sociedade contemporânea vem constituindo um ser humano anônimo e alienado.

Quanto mais complicada e refinada a aparelhagem social, econômica e científica, para cujo manejo o corpo já há muito foi ajustado pelo sistema de produção, tanto mais empobrecidas as vivências de que ele é capaz (Horkheimer e Adorno, 1985, p. 47).

A lógica de produção em massa gerou tecnologias capazes de despersonalizar o indivíduo na massa, tor- nando-o substituível. Simultaneamente, a introdução das sofisticadas técnicas científicas de gestão também possibilitou o afastamento dos capitalistas do controle dos meios de produção. A alienação do trabalho atingiu tanto os funcionários quanto seus patrões. A racionalização da produção trouxe, portanto, outro aspecto ideológico, a saber: a redução da sociedade ao controle técnico por parte de um grupo social dominante. De acordo com Marcuse (1973, p. 49): "A dominação se transfigura em administração [...] A fonte tangível de exploração desaparece por trás da fachada de racionalidade objetiva".

Tragtenberg (1985) demonstrou, por meio de uma análise histórica dos modos de produção, que a organização burocrática passou de um instrumento de mediação a uma forma de dominação a serviço das forças sociais hegemônicas no capitalismo, cuja expressão ideológica é a própria Teoria Geral da Administração, que constitui enunciados parciais restritos a um dado momento do processo capitalista de produção. Esses enunciados tornam absolutas as formas hierárquicas da empresa capitalista; nesta, o capital é considerado como um bem de produção inerente ao processo produtivo, e não como uma relação social; já o trabalho, este é considerado como um complemento do capital, ao passo que a burocracia hierárquica é compreendida como uma expressão natural da divisão social do trabalho.

Outra faceta da ideologia dos administradores é a naturalização de sua condição de dominação, por meio da naturalização da divisão social do trabalho. "O poder tecnocrático surge como poder da natureza" (Tragtenberg, 1985, p. 217). Na mesma linha, Alvesson (1987) mostrou que os administradores armam-se de uma ideologia gerencialista. Tal ideologia integra-se a uma ideologia elitista, que enfatiza a função administrativa não apenas como diferenciada, mas também como a mais importante para a organização. E não é por outro motivo que os administradores são identificados como seres de qualidades e qualificações raras - portanto, legítimos detentores de seus poderes, status e privilégios.

Essa naturalização promove tanto a negação dos conflitos quanto a idéia de que os conflitos são uma patogenia, devendo, por esse motivo, ser preventivamente evitados (Alvesson, 1987). Dessa maneira, os diversos teóricos da administração procuram, por meio de técnicas de gestão "científicas", criar as condições para que os administradores antecipem-se aos conflitos, limitando-os, no máximo, a uma existência latente (Tragtenberg, 1985). 


\section{0 mito da democracia racial brasileira}

A segunda ideologia que se analisa aqui diz respeito ao mito da democracia racial brasileira, que, segundo Oliveira (2000), começou a ser engendrado na década de 1930. O incipiente processo de industrialização brasileiro atrelou-se a transformações políticas e econômicas no sentido de criar "ondas de modernização" que deslocassem a vida social do campo para a cidade. Para o Brasil se transformar em um país urbano e moderno, era necessário criar um Estado forte, capaz de modelar seu conjunto populacional no sentido de se conseguir elevação da qualidade de vida, melhoria educacional e adestramento técnico-profissional, alargamento dos setores médios, ocupação territorial e unidade lingüística, cultural e de identidade nacional.

Dessa maneira, a elite intelectual brasileira da década de 1930 passou a defender a idéia de que um projeto de desenvolvimento viável para o Brasil só seria bem-sucedido pela aceitação do caráter mestiço da sociedade brasileira, apresentando-a como um cruzamento de identidades entre brancos, negros e índios, convivendo de forma harmoniosa. Como sugere Oliveira (2001), o aspecto mais curioso da idéia da democracia racional é que ela não está baseada em aspectos políticos, mas em elementos estritamente simbólicos.

O mito da democracia racial passou a anunciar o Brasil como o país da convivência harmônica entre brancos, negros e índios. Isso se refletiu inclusive nas esferas político-partidárias: tanto a direita quanto a esquerda afirmavam que a discriminação racial não era problema para os brasileiros (Munanga, 1996; Soares, 2000). Esse processo reflete-se, por exemplo, nas condições de inclusão econômica dos negros. Os dados em relação à educação do último Censo Demográfico são reveladores. A taxa de analfabetismo em 1999 é mais elevada entre negros e pardos - $20 \%$ - do que entre brancos - 8,3\% (IBGE, 2001).

Esses dados quantitativos sobre a questão racial foram ocultados durante um certo tempo. Os censos não contabilizavam a informação sobre etnia/raça. Depois, passaram a perguntar para o entrevistado qual era sua raça (Piza e Rosenberg, 2002). No Brasil, a raça é ideologicamente atribuída ao fenótipo, e não ao genótipo. Assim, a partir das características corporais, são criadas definições de raça que negam o fato de ser negro por exemplo, a expressão "café com leite". Essas definições ocultam a afroascendência e prometem uma possibilidade de identificação com a raça branca, promovendo uma espécie de "ideologia do branqueamen- to" - quando os negros buscam negar sua origem étnica para copiar o modelo ideal branco. No entanto, quando se trata de discriminação, a diferença entre brancos e negros é nítida, como demonstram os dados do IBGE (Bento, 2002).

\section{Crítica da gestão da diversidade}

Quando, nos anos 1960, os movimentos de defesa dos direitos civis norte-americanos conseguiram aprovar leis que preconizavam uma discriminação positiva das minorias, forçou-se a reconhecer o preconceito como algo institucionalizado. Assim sendo, somente por meio de reformas institucionais - a implementação de políticas de ação afirmativa - o preconceito poderia ser superado, pelo menos em seus efeitos no mercado de trabalho. Mas esse é um mecanismo que ameaça o sistema de reprodução do capital, pois as políticas de ação afirmativa passaram a constituir uma variável externa e incontrolável, que se impunha à lógica do sistema capitalista de produção e consumo de mercadorias.

Embora o capitalismo não distinga as identidades de consumidores e trabalhadores, a não-discriminação é contrária à prática capitalista. Os mecanismos de recrutamento e seleção representam a face visível da contradição da ação afirmativa com a lógica de mercado, pois é mais custoso recrutar as pessoas discriminadas do que apenas buscar os trabalhadores disponíveis no mercado. Os discriminados são menos abundantes na qualificação requerida às ocupações valorizadas e o custo de selecionar e recrutar a partir de uma lógica estranha ao mercado é uma das raízes das restrições à ação afirmativa, raízes estas ancoradas no argumento de que as ações afirmativas ameaçam o sistema de mérito.

A ação afirmativa representou uma ruptura na afirmação da discriminação nos Estados Unidos por incluir critérios de eqüidade onde só existia a divisão do trabalho. A partir de então, as empresas deveriam incluir, nos procedimentos de recrutamento e seleção, critérios não discriminatórios, uma vez que as empresas são consideradas instrumentos de modificação da sociedade. $\mathrm{Na}$ organização capitalista do trabalho, o papel dos indivíduos sempre esteve atrelado à sua utilidade para a reprodução do capital, para a qual não há diferença em termos étnicos, sexuais e religiosos, desde que produzam e consumam. A atribuição de privilégios de classe, contudo, sempre esteve ligada à manipulação de interesses e fidelidades. As diferenças sempre foram cultivadas dentro da lógica funcionalista da gestão, apesar da roupagem de igualdade para todos. 
A partir do momento em que a contratação de pessoas vindas de minorias tornou-se inevitável, os administradores procuraram incorporar a novidade ao sistema administrativo por meio das políticas de gestão da diversidade, de forma a se anteciparem ao conflito. A gestão da diversidade tornou-se, então, parte integrante da ideologia dos administradores. Se, no contexto norte-americano, as ações afirmativas expuseram uma tensão interna que não podia mais ser negada ou abolida, a adoção da gestão da diversidade pelas empresas buscou deslocar a questão de um conflito político, incontrolável, para uma variável interna, funcional e controlável. Essa transformação inscreve-se nas estratégias burocráticas de antecipação de conflitos de caráter coletivo, resultado da ideologia tecnocrática, uma vez que se incentiva a competição entre os indivíduos, para reduzir a potencialidade do conflito estrutural.

A gestão da diversidade não é uma mera manifestação clássica de ideologia tecnocrática, uma vez que seu caráter prático parece indicar sua natureza diferente. É mais prático admitir a diferença entre as pessoas na força de trabalho, aceitando-a como um fato, e, simultaneamente, criar estratégias para controlá-la. Assim sendo, a diferença é explicitada, mas de modo reduzido. O contexto da diferença, sua história e seu lugar social, não são discutidos; há apenas um conjunto de técnicas para lidar com um fato tomado como absoluto. A gestão da diversidade passa a integrar o conteúdo da ideologia tecnocrática.

Aqui reside, portanto, o argumento ideológico central da gestão da diversidade. O termo gestão abrange todas as operações necessárias para medir e controlar certo objeto - no caso, a diversidade. A redução de um problema social à dimensão técnica elimina o caráter político da questão. Elimina-se a ameaça da ruptura da unidimensionalidade pela ação afirmativa com a aceitação da idéia de diversidade como vantagem competitiva. A diferença neutralizada transforma-se em mercadoria e pode ser gerenciada como um recurso da organização.

\section{A crítica da gestão da diversidade no Brasil}

A transposição de práticas norte-americanas para outros contextos é, por si só, ideológica, uma vez que procura dar um caráter universal às práticas de gestão, desconsiderando o momento histórico e social do país. Quanto à gestão da diversidade, a ideologia é ainda mais ressaltada porque a redução do conteúdo político da idéia de gestão da diversidade soma-se à pró- pria negação da existência do racismo e do preconceito de gênero. Essa combinação cria contradições originais no Brasil, principalmente em multinacionais norte-americanas, que procuram implantar, em solo brasileiro, políticas de gestão da diversidade idênticas ao modelo da matriz.

No Brasil não é possível empregar diretamente um programa de gestão da diversidade sem que ocorra uma climatização, devido à dificuldade histórica de identificar alguns grupos discriminados. O mito da democracia racial brasileira dificulta o reconhecimento da discriminação e, por conseqüência, a identificação dos negros a serem recrutados e selecionados. A gestão da diversidade precisa afirmar a própria existência da discriminação para se justificar, o que a coloca em tensão com a ideologia da democracia racial. Sem o reconhecimento da discriminação, não há sobre o que construir um discurso de igualdade de acesso ao trabalho.

A ambigüidade do discurso gerencial sobre a negação do racismo traduz-se na seguinte racionalização: não há preconceito contra negros; o que existe é uma falta de negros qualificados para ocupações valorizadas. Não há um feliz casamento entre as duas formações ideológicas, uma vez que a gestão da diversidade não é uma ideologia no mesmo sentido da democracia racial. Os comportamentos tolerantes com a diferença precisam ser, portanto, ensinados na organização. Assim sendo, resta à empresa, para cumprir eficientemente o programa implementado por exigência da matriz, criar condições para a contratação de negros por meio da adoção de alguns eleitos oriundos do ensino público, qualificados por um curso superior.

No Brasil opera-se uma mudança ideológica. Antes, a ideologia vigente era o mito da democracia racial que negava a existência das discriminações. Agora, a nova ideologia é a da diversidade administrada. Enquanto o mito da democracia racial pressupõe uma negação das diferenças por meio da miscigenação, a diversidade revela a discriminação para, em seguida, ensinar a tolerância.

\section{CONCLUSÃO}

$\mathrm{O}$ intuito do presente artigo não foi estabelecer um conceito de diversidade, nem mesmo eleger um conceito existente como o mais adequado, muito menos aprimorá-lo. Pelo contrário, foi apontar o caráter ideológico da gestão da diversidade, que parece predomi- 
nar nos contextos internacional e local, desconsiderando as limitações infligidas pelo preconceito ao convívio entre pessoas de grupos discriminadores e discriminados.

O determinismo técnico inserido no discurso da gestão da diversidade reproduz a lógica da máxima eficiência econômica presente na ideologia tecnocrática. A inclusão das minorias adapta-se à lógica produtiva: primeiro, as diferenças transformam-se em vantagem competitiva; em seguida, são transformadas em um recurso - a diversidade - que pode ser gerenciado. Por fim, as diferenças são neutralizadas ao serem transportadas para o campo em que todas as coisas são mercadorias.

Pode-se argumentar, por outro lado, que, especialmente no Brasil, onde não houve ações afirmativas efetivas, os programas de diversidade teriam o mérito de trazer benefícios a algumas pessoas discriminadas, uma vez que, por meio de iniciativas de gestão da diversidade, essas mesmas pessoas podem conseguir seu primeiro emprego, ou direitos que lhes são negados cotidianamente. Programas de diversidade, ao serem implementados em algumas organizações, permitiriam essa novidade. Criticá-los, esquecendo essas possibilidades, seria "injusto".

Porém, a crítica da gestão da diversidade é necessária. As ações afirmativas poderiam vir a ser um movimento de ruptura da dominação, pois quebrariam a padronização da força de trabalho realizada pela organização da produção. Ocorre que esse potencial emancipatório desmancha-se no ar pela força da lógica da gestão da diversidade diluída na ideologia tecnocrática. Combinada ao mito da democracia racial, a gestão da diversidade contribui para a negação do preconceito por meio da redução das diferenças à forma de mercadoria, realizando um movimento de reificação das relações sociais.

Espera-se que o presente trabalho incentive novas pesquisas a aprofundarem a temática da diversidade nas organizações brasileiras. Sugere-se que sejam estudados casos de implementação de políticas de gestão da diversidade que abranjam não apenas questões de raça e etnia, mas também outras formas de inclusão do diferente. Outra vertente de pesquisa que parece promissora é entender a gestão da diversidade como uma forma de deslocar questões políticas, pertencentes à esfera pública, para a esfera das empresas, em um processo de privatização do social.

Por fim, é necessário apontar que, apesar do caráter reducionista e naturalizador de seus conteúdos, a gestão da diversidade não esgota a possibilidade de emancipação das pessoas. A convivência em organizações menos homogêneas tem o potencial de gerar questionamentos que, de forma paradoxal, podem trazer novas formas de resistência à tendência de regressão contidas na própria gestão da diversidade.

\section{REFERÊNCIAS BIBLIOGRÁFICAS}

ALVESSON, M. Organizational theory and technocratic consciousness. Berlin: Walter de Gruyter, 1987.

AUSTIN, J. R. A cognitive framework for understanding demographic influences in groups. International Journal of Organizational Analysis, v. 5, n. 4, p. 342-59, 1997.

BARDIN, L. Análise de conteúdo. Lisboa: Edições 70, 1977.

BARRY, B.; BATEMAN, T. S. A social trap analysis of the management of diversity. The Academy of Management Review, v. 21, n. 3, p. 757-791, 1996.

BENTO, M. A. S. Ação afirmativa e diversidade no trabalho. São Paulo: Casa do Psicólogo, 2000.

BENTO, M. A. S. Branqueamento e branquitude no Brasil. In CARONE, I.; BENTO, M. A. S. Psicologia social do racismo. Petrópolis: Vozes 2002.

COX JR., T.; BLAKE, S. Managing diversity: implications for organizational competitiveness. Academy of Management Executive, v. 5, n. 3, p. 45-57, 1991.

ELLIS, C. Affirmative action and the dilemma of the "qualified". Black Enterprise, v. 25, n. 3, p. 158-163, 1994.

FLEURY, M. T. L. Gerenciando a diversidade cultural: experiências de empresas brasileiras. In: ENCONTRO ANUAL DA ASSOCIAÇÃO NACIONAL DOS PROGRAMAS DE PÓS-GRADUAÇÃO EM ADMINISTRAÇÃO, 23․, 1999, Foz do Iguaçu. Anais... Foz do Iguaçu: Anpad, 1999. CD-ROM.

FLEURY, M. T. L. Gerenciando a diversidade cultural: experiências de empresas brasileiras. Revista de Administração de Empresas, v. 40, n. 3 , 2000.

GILBERT, J. A.; STEAD, B. A.; IVANCEVICH, J. M. Diversity management: a new organizational paradigm. Journal of Business Ethics, v. 21 n. 1, p. 6177, 1999.

HELD, D. Introduction to critical theory: Horkheimer to Habermas. Berkeley: University of California, 1980.

HODGES-AEBERHARD, J. Affirmative action in employment: recent court approaches to a difficult concept. International Labor Review, Geneva, v. 138 , n. 3, p. 247-73, 1999.

HORKHEIMER, M.; ADORNO, T. W. Dialética do esclarecimento. São Paulo: Paz e Terra, 1985. 
HUMAN, L. The development of black and female managers in South Africa: why many affirmative action programs fail. Management Education and Development, v. 24, n. 2, p. 153-67, 1993.

IBGE. Síntese de indicadores sociais. Disponível em: <http:// www.ibge.gov.br>. Acesso em: 04 abr. 2001.

KELLY, E.; DOBBIN, F. How affirmative action became diversity management. American Behavior Scientist, v. 41, n. 7, p. 960-85, 1998.

MARCUSE, H. A ideologia da sociedade industrial. Rio de Janeiro: Zahar, 1973.

MARX, K.; ENGELS, F. A ideologia alemã. São Paulo: Martins Fontes, 1998.

MILLIKEN, F. J.; MARTIN, L. L. Searching for common threads: understanding the multiple effects of diversity in organizational groups. The Academy of Management Review, v. 21, n. 2, p. 402-34, 1996.

MINISTÉRIO DO TRABALHO. Getedeo. Disponível em: <http:// www.mtb.gov.br/gm/getedeo/default.htm>. Acesso em: 24 fev. 2001.

MUNANGA, K. Anti-racismo no Brasil. In: MUNANGA, K. (Org.). Estratégias e políticas de combate à discriminação racial. São Paulo: Edusp, 1996

NEWMAN, M. A. Sex, race, and affirmative action: an uneasy alliance. Public Productivity \& Management Review, v. 20, n. 3, p. 295-308, 1997.

NKOMO, S. M.; COX JR., T. Diversidade e identidade nas organizações. In: CLEGG, S.; HARDY, C.; NORD, W. Handbook de estudos organizacionais. São Paulo: Atlas, 1999.

OLIVEIRA, E. H. P. Além do nada: Estado, raça e ação afirmativa. Disponível em: <http://www.intelecto.net/cidadania/nada.htm>. Acesso em: $5 \mathrm{fev}$. 2001

Artigo recebido em 03.11.2002. Aprovado em 28.11.2003.
PIZA, E.; ROSENBERG, F. Cor nos censos brasileiros. In: CARONE, I.; BENTO, M. A. S. Psicologia social do racismo. Petrópolis: Vozes, 2002.

SCHNEIDER, S. K.; NORTHCRAFT, G. B. Three social dilemmas of workforce diversity in organizations: a social identity perspective. Human Relations, v. 52, n. 11, p. 1445-1468, 1999.

SCOTT, C. R.; AMOS, T.; SCOTT, J. D. Affirmative action as seen by business majors in the U.S. and South Africa. S.A.M. Advanced Management Journal, Cincinnati, v. 63, n. 3, p. 28-39, 1998.

SOARES, V. Ações afirmativas para mulheres na política e no mundo do trabalho no Brasil. In: BENTO, M. A. S. Ação afirmativa e diversidade no trabalho. São Paulo: Casa do Psicólogo, 2000.

THOMAS, R. R. From affirmative action to affirmative diversity. Harvard Business Review, Mar./Apr., p. 107-118, 1990.

THOMAS, R. R. Beyond race and gender: unleashing the power of your total work force by managing diversity. New York: Amacom, 1991. Citado por NKOMO, S. M.; COX Jr., T. Diversidade e identidade nas organizações. In: CLEGG, S.; HARDY, C.; NORD, W. Handbook de estudos organizacionais. São Paulo: Atlas, 1999.

TRAGTENBERG, M. Burocracia e ideologia. São Paulo: Ática, 1985.

WENTLING, R. M.; PALMA-RIVAS, N. Current status and future trends of diversity initiatives in the workplace: diversity experts' perspective. Human Resource Development Quarterly, v. 9, n. 3, p. 35-61, 1998.

WISE, L. R.; TSCHIRHART, M. Examining empirical evidence on diversity effects: how useful is diversity research for public-sector managers? Public Administration Review, v. 60, n. 5, p. 386-95, 2000.

\section{Mario Aquino Alves}

Professor da Universidade Presbiteriana Mackenzie e da FGV-EAESP. Doutor em Administração de Empresas pela FGV-EAESP. Interesses de pesquisa em Estudos Críticos em Administração, teoria das organizações e organizações da sociedade civil.

E-mail: maalves@fgvsp.br

Endereço: Av. Nove de Julho, 2.029, 9ª andar, Bela Vista, São Paulo - SP, 01313-902.

\section{Luis Guilherme Galeão-Silva}

Professor da FGV-EAESP. Doutorando em Psicologia Social pela PUC-SP. Mestre em Psicologia pela USP. Interesses de pesquisa em gestão da diversidade e preconceito.

E-mail: luisgaleao@fgvsp.br

Endereço: Av. Nove de Julho, 2.029, $9^{\circ}$ andar, Bela Vista, São Paulo - SP, 01313-902. 